\title{
AWARENESS AND KNOWLEDGE OF GLAUCOMA AMONG ADULT PATIENTS AT THE EYE CLINIC OF A TEACHING HOSPITAL
}

\author{
G. NKUM ${ }^{1}$, S. LARTEY ${ }^{2}$, C. FRIMPONG ${ }^{3}$, F. MICAH ${ }^{2}$ AND B. NKUM ${ }^{2}$ \\ ${ }^{1}$ Komfo Anokye Teaching Hospital, ${ }^{2}$ Kwame Nkrumah University of Science and Technology. College of \\ health Science, ${ }^{3}$ Garden City University, College of Nursing, Kumasi, Ghana
}

DOI: http://dx.doi.org/10.4314/gmj.v49i3.11

Corresponding Author: Dr. Seth Lartey

Email: sylartey.chs@knust.edu.gh

Conflicts of interest: None declared

\section{SUMMARY}

Background: Primary open angle glaucoma (POAG) is an irreversible blinding disease that often presents late because it is symptomless in the early stages. Prognosis depends on early diagnosis and treatment and patient understanding of their condition. Many patients present late because of poor awareness and knowledge. This study was conducted to assess patient's awareness and knowledge of glaucoma in a referral Teaching Hospital.

Methods: Descriptive cross-sectional study conducted among glaucoma patients aged 40 years and above attending the Komfo Anokye Teaching Hospital (KATH). Patients were selected by simple random sampling. They were recruited after informed consent had been given. A questionnaire on demographics, socio-economics and awareness of glaucoma was administered.

Results: There were a total of 117 participants, 61 males and 56 females. The median and modal age group was 50 and 59 years. Amongst the participants, $74 \%$ were aware of glaucoma. There were no significant statistical difference in the various age groups, sex, ethnic group or religion and their awareness of glaucoma $(\mathrm{P}>0.05)$. There were statistically significant differences between those who had higher education and their awareness of glaucoma $(\mathrm{P}<0.001)$. Yet only $27 \%$ of these had accurate knowledge of glaucoma.

Conclusion: Glaucoma awareness in patients attending Komfo Anokye Teaching Hospital is high. Higher education was associated with higher awareness yet this was not translated into accurate knowledge as there were significant misconceptions. There is the need to review the contents of health education with the aim of reducing dangerous misconception of glaucoma and targeting the lower socioeconomic population.

Key words: Glaucoma, Primary Open Angle Glaucoma, Knowledge, Awareness, Blindness

\section{INTRODUCTION}

Glaucoma is the second leading cause of blindness after cataract and the leading cause of irreversible blindness in the world. ${ }^{1}$ Diagnosis is often made at the late stage of the condition when much damage to the eye has already occurred. Raising the public level of awareness through public education for periodic eye checks is one of the effective measures for its early detection and management. The World Health Organization (WHO) estimated the incidence of Primary Open Angle Glaucoma (POAG) at 2.4 million people per year. It is the most prevalent of all the glaucomas affecting the general population over the age of forty years and increases with age. Blindness prevalence for all types of glaucoma was estimated at 5.2 million people with 3 million cases caused by POAG. POAG represents a significant public health problem. POAG is an important cause of blindness and the most frequent cause of irreversible blindness in blacks. ${ }^{2}$

The highest prevalence for POAG so far reported is in the black populations of the Caribbean. ${ }^{3,4}$ The likelihood of developing POAG increases 4.5 times after 40 years of age. ${ }^{5}$ A positive family history is a major risk factor for the development of POAG.). POAG can occur at all levels of intraocular pressure (IOP). The higher the IOP, the more likely advanced POAG is to occur, the more severe it is and the more likely it is to worsen progressively. ${ }^{6}$ In Ghana, the prevalence of blindness in people over 40 years is between $7.6 \%$ and $8.5 \%{ }^{6,7}$ This is consistent with what has been found in Barbados in individuals 40 years and above $7 \%{ }^{8}$, and in St Lucia in those 30 years and above $8.8 \% \%^{3}$. In this study, glaucoma was the leading cause of blindness affecting 21 of the 102 bilaterally blind individuals (20.6\%). Reports from Togo ${ }^{9}$ and Cameroun ${ }^{10}$ are similar. In both, glaucoma was the second leading cause of blindness. 
Ghana has been identified as one of the countries on the African continent most affected by glaucoma. In Ghana an estimated 600, 000 people are said to be suffering from glaucoma. Out of the number, 30, 000 are likely to become blind if the disease is left untreated. The prevalence rate of the disease among people above forty years is $8.5 \%$ and those above 30years being $7.7 \%$. ${ }^{11}$ Up to $50 \%$ of glaucoma patients are already blind in one eye at first presentation in Africa. ${ }^{12}$

Diagnosis of glaucoma is usually made at the advanced stage as most new cases present late when there is already significant visual loss. The aim of this study is to assess the level of awareness and knowledge of glaucoma in patients aged forty years and above and to identify possible factors contributing to the level of awareness. The specific objectives were to determine the level of awareness of glaucoma among eye patients, to determine the level of knowledge of glaucoma among eye patients, to determine the socio- economic factors associated with glaucoma awareness among eye patients, to determine the socio economic factors associated with glaucoma knowledge among eye patients and to determine the sources of information for glaucoma knowledge Prognosis of POAG depends primarily on the stage the condition is diagnosed.

If patients are aware of the risk factors and presentation of glaucoma, there will be less late presentation of the disease and therefore less blindness due to glaucoma. No study has been done on glaucoma awareness in the Ashanti region of Ghana and at the Komfo Anokye Teaching Hospital .This is required to help develop new educational strategies targeted to ultimately reduce late diagnosis of this potentially blinding condition.

\section{METHODS}

This was a descriptive cross sectional study conducted in the eye clinic of Komfo Anokye Teaching Hospital (KATH).KATH is located in Kumasi, the Regional Capital of Ashanti Region of Ghana with a total projected population of $3,187,607 .{ }^{13}$ The geographical location of the 1205-bed capacity teaching hospital, the road network of the country and commercial nature of Kumasi makes the hospital accessible to all the areas that share boundaries with Ashanti Region and others that are further away. As such referrals are received from the three Northern Regions (Northern, Upper East and Upper West Regions), Brong Ahafo, Central, Western and parts of Volta Region. Adult patients aged 40years and above who were attending the Eye Clinic were included in the study. The sample size was calculated assuming an estimated level of awareness of $7 \%$, a confidence level of $95 \%$ and a margin of allowable error of $5 \%$. This gave an estimated size of 100 . A sample size of 120 was expected to be recruited to allow for attrition. One hundred and seventeen (117) participants were selected by simple random sampling. A structured questionnaire was used to gather information on patient's demographics, socioeconomic status, knowledge and awareness of glaucoma Awareness were measured by asking participants whether or not they had heard of glaucoma. Knowledge was measured by asking participants to indicate which of the clinical presentations and risk factors of glaucoma that they already knew of.

Informed consent was sought from the patients before the questionnaire was administered. The questionnaire was administered in the local language to participants who could not read after adequate explanation. For those who could read and write self-administration was done. The data was double entered into Epi-Info software. It was then transferred into Statistical Package for the social science (spss) (version 16) for statistical analysis and graphics.

\section{RESULTS}

Table 1 Demographic Characteristics of respondents

\begin{tabular}{|c|c|c|}
\hline \multicolumn{3}{|c|}{ Demographic Characteristics of respondents } \\
\hline Variable & Frequency $(\mathrm{n}=117)$ & Percentage \\
\hline \multicolumn{3}{|l|}{ Age (years) } \\
\hline $40-49$ & 37 & 32 \\
\hline $50-59$ & 39 & 33 \\
\hline $60-69$ & 28 & 24 \\
\hline 70 and above & 13 & 11 \\
\hline \multicolumn{3}{|l|}{ Gender } \\
\hline Male & 61 & 52 \\
\hline Female & 56 & 48 \\
\hline \multicolumn{3}{|l|}{ Ethnicity } \\
\hline Ashanti & 74 & 63 \\
\hline Fanti & 12 & 10 \\
\hline $\mathrm{Ga}$ & 10 & 9 \\
\hline Others & 21 & 18 \\
\hline \multicolumn{3}{|l|}{ Education } \\
\hline None & 15 & 13 \\
\hline Primary school & 15 & 13 \\
\hline Middle school & 36 & 31 \\
\hline Secondary school & 23 & 20 \\
\hline Tertiary level & 28 & 23 \\
\hline \multicolumn{3}{|l|}{ Occupation } \\
\hline Self Employed & 61 & 52 \\
\hline Civil/ Public Servant & 31 & 27 \\
\hline Retired & 19 & 16 \\
\hline Others & 6 & 5 \\
\hline \multicolumn{3}{|l|}{ Income Levels } \\
\hline Less than $\mathrm{GH} \phi 100$ & 30 & 26 \\
\hline Between GHф100-299 & 48 & 43 \\
\hline Between GHc 300-500 & 13 & 11 \\
\hline More than $\mathrm{GH} \phi 500$ & 22 & 20 \\
\hline
\end{tabular}


There were a total of 117 participants, 61 males and 56 females. Thirty-nine participants $(33 \%)$ were in the age group of 50-59 years being the highest with least being $13(11 \%)$ in the 70 and above age group. The median and modal age group was the 50-59 year group.

More respondents were from Ashanti ethnicity with the least respondents coming from the Ga. This may be because the study was done in Kumasi, the regional capital of Ashanti Region. Eighty seven participants (74\%) had heard of the word glaucoma or high pressure in the eye while $30(26 \%)$ had never heard of it. From Table 2 there were no statistically significant difference in the various age groups and their awareness of glaucoma $(\mathrm{p}>0.05)$.

Table 2 Age group and awareness of glaucoma

\begin{tabular}{|l|l|l|l|l|}
\hline & $\begin{array}{l}\text { No } \\
(\mathbf{n}=\mathbf{3 0})\end{array}$ & $\begin{array}{l}\text { Yes } \\
(\mathbf{n = 8 7})\end{array}$ & $\begin{array}{l}\text { All } \\
(\mathbf{n = 1 1 7})\end{array}$ & $\mathbf{P}$ \\
\hline $\begin{array}{l}\text { Age } \\
\text { Group }\end{array}$ & $\begin{array}{l}\text { Number } \\
(\%)\end{array}$ & $\begin{array}{l}\text { Number } \\
(\%)\end{array}$ & $\begin{array}{l}\text { Number } \\
(\%)\end{array}$ & $\chi^{2}$ test \\
\hline $40-49$ & $10(33.3)$ & $27(31.0)$ & $37(31.6)$ & 0.82 \\
\hline $50-59$ & $11(36.7)$ & $28(32.2)$ & $39(33.3)$ & 0.65 \\
\hline $60-69$ & $7(23.3)$ & $21(24.1)$ & $28(23.9)$ & 0.93 \\
\hline$\geq 70$ & $2(6.7)$ & $11(12.6)$ & $13(11.1)$ & 0.34 \\
\hline
\end{tabular}

Table 3 Sex and awareness of glaucoma

\begin{tabular}{|l|l|l|l|l|}
\hline & $\begin{array}{l}\text { No } \\
(\mathbf{n = 3 0 )}\end{array}$ & $\begin{array}{l}\text { Yes } \\
(\mathbf{n}=\mathbf{8 7})\end{array}$ & $\begin{array}{l}\text { All } \\
(\mathbf{n = 1 1 7})\end{array}$ & $\mathbf{P}$ \\
\hline Gender & $\begin{array}{l}\text { Number } \\
(\mathbf{\%})\end{array}$ & $\begin{array}{l}\text { Number } \\
(\%)\end{array}$ & $\begin{array}{l}\text { Number } \\
(\%)\end{array}$ & $\chi^{\mathbf{2} \text { test }}$ \\
\hline Male & $16(53.3)$ & $45(51.7)$ & $61(52.1)$ & 0.88 \\
\hline Female & $14(46.7)$ & $42(48.3)$ & $56(47.9)$ & 0.88 \\
\hline
\end{tabular}

There was no statistical significant sex difference in the awareness of glaucoma (Table 3). Of the 87 participants who were aware of glaucoma 45 (52\%) were males and $42(48 \%)$ were females $(\mathrm{P}=0.88)$.

Table 4 Ethnic group and awareness of glaucoma

\begin{tabular}{|l|l|l|l|l|}
\hline & $\begin{array}{l}\text { No } \\
(\mathbf{n = 3 0 )}\end{array}$ & $\begin{array}{l}\text { Yes } \\
(\mathbf{n = 8 7})\end{array}$ & $\begin{array}{l}\text { All } \\
(\mathbf{n = 1 1 7})\end{array}$ & $\mathbf{P}$ \\
\hline Ethnicity & $\begin{array}{l}\text { Number } \\
(\%)\end{array}$ & $\begin{array}{l}\text { Number } \\
(\%)\end{array}$ & $\begin{array}{l}\text { Number } \\
(\%)\end{array}$ & $\chi^{2}$ test \\
\hline Ashanti & $18(60.0)$ & $56(64.4)$ & $74(63.3)$ & 0.67 \\
\hline Fanti & $4(13.3)$ & $8(9.2)$ & $12(10.3)$ & 0.52 \\
\hline Ewe & $1(3.3)$ & $9(10.3)$ & $10(8.5)$ & 0.24 \\
\hline Others & $7(23.3)$ & $14(16.1)$ & $21(17.9)$ & 0.37 \\
\hline
\end{tabular}

Majority of the subjects were Ashantis (63\%), 10\% were Fantis, 9\% Ewes and 18\% were from other Ghanaian ethnic groups such as Akwapim, Brong, Mamprusi and Frafra. The proportion of the various ethnic groups among those who were aware of glaucoma was also similar.
There were no significant ethnic difference between those who had heard of glaucoma and those who had not (Table 4).

Table 5 Education and awareness of glaucoma

\begin{tabular}{|l|l|l|l|l|}
\hline & $\begin{array}{l}\text { No } \\
(\mathrm{n}=30)\end{array}$ & $\begin{array}{l}\text { Yes } \\
(\mathrm{n}=87)\end{array}$ & $\begin{array}{l}\text { All } \\
(\mathrm{n}=117)\end{array}$ & $\mathrm{P}$ \\
\hline Education & $\begin{array}{l}\text { Number } \\
(\%)\end{array}$ & $\begin{array}{l}\text { Number } \\
(\%)\end{array}$ & $\begin{array}{l}\text { Number } \\
(\%)\end{array}$ & $\chi^{2}$ test \\
\hline None & $3(10.0)$ & $12(13.8)$ & $15(12.8)$ & 0.59 \\
\hline Primary & $6(20.0)$ & $9(10.3)$ & $15(12.8)$ & 0.17 \\
\hline Middle & $17(56.7)$ & $19(21.8)$ & $36(30.8)$ & $<0.001$ \\
\hline Secondary & $4(13.3)$ & $19(21.8)$ & $23(19.7)$ & 0.31 \\
\hline Tertiary & $0(0)$ & $28(32.2)$ & $28(23.9)$ & $<0.001$ \\
\hline
\end{tabular}

The education level of participants ranged from no formal education to the tertiary level. The majority, 36 (31\%), had completed middle school and this was followed by those who had had tertiary education, 28 (24\%). There were statistically significant differences between these two major groups as far as their awareness of glaucoma was concerned. The tertiary group were all aware of glaucoma while the majority of participants who were unaware of glaucoma, $17(57 \%)$ belonged to the middle school group. Of those with no formal education 12 (14\%) had heard of glaucoma while only $3(10 \%)$ had never heard of glaucoma, though this difference was not statistically significant (Table 5).

Table 6 Occupational and awareness of glaucoma

\begin{tabular}{|l|l|l|l|l|}
\hline & $\begin{array}{l}\text { No } \\
(\mathrm{n}=30)\end{array}$ & $\begin{array}{l}\text { Yes } \\
(\mathrm{n}=87)\end{array}$ & $\begin{array}{l}\text { All } \\
(\mathrm{n}=117)\end{array}$ & $\mathrm{P}$ \\
\hline Occupation & $\begin{array}{l}\text { Number } \\
(\%)\end{array}$ & $\begin{array}{l}\text { Number } \\
(\%)\end{array}$ & $\begin{array}{l}\text { Number } \\
(\%)\end{array}$ & $\chi^{2}$ test \\
\hline Self employed & $21(70.0)$ & $40(46.0)$ & $61(52.1)$ & 0.02 \\
\hline $\begin{array}{l}\text { Civil/Public } \\
\text { servant }\end{array}$ & $2(6.7)$ & $29(33.3)$ & $31(26.5)$ & $<0.01$ \\
\hline Retired & $2(6.7)$ & $17(19.5)$ & $19(16.2)$ & 0.10 \\
\hline Other & $5(16.7)$ & $1(1.2)$ & $6(5.1)$ & $<0.001$ \\
\hline
\end{tabular}

From Table 6, more than half of the study subjects were self-employed, 61 (52\%), 31 (27\%) were civil or public servants, $19(16 \%)$ were retired citizens while 6 (5\%) were farmers and a linguist There were statistically significant occupation differences as far as awareness was concerned. Most of the people who had never heard of glaucoma were self-employed, 21 (70\%) compared to, $40(46 \%)$ of those who had heard of glaucoma. Only 2 of the civil or public servants (7\%) were not aware of glaucoma compared to 29 (33\%) who were aware. 
Table 7 shows the level of income of participants and their awareness of glaucoma. There were statistically significant differences between the group, which responded yes and those who responded no to whether they were aware of glaucoma. Most of the participants earned between 100 and 299 Ghana cedis, 48 (43\%), and there were no statistically significant difference in this group.

In the less than 100 Ghana cedis group $13(43 \%)$ were not aware of glaucoma compared to 17 (21\%) who were aware. All the participants in the 300 to 500 Ghana cedi group were all aware of glaucoma while only 2 people $(7 \%)$ in the more than 500 Ghana cedi group had never heard of glaucoma.

Table 7 Income level and awareness of glaucoma

\begin{tabular}{|l|l|l|l|l|}
\hline & $\begin{array}{l}\text { No } \\
(\mathrm{n}=30)\end{array}$ & $\begin{array}{l}\text { Yes } \\
(\mathrm{n}=87)\end{array}$ & $\begin{array}{l}\text { All } \\
(\mathrm{n}=117)\end{array}$ & $\mathrm{P}$ \\
\hline $\begin{array}{l}\text { Income Level } \\
\text { (Ghana Cedis) }\end{array}$ & $\begin{array}{l}\text { Number } \\
(\%)\end{array}$ & $\begin{array}{l}\text { Number } \\
(\%)\end{array}$ & $\begin{array}{l}\text { Number } \\
(\%)\end{array}$ & $\chi^{2}$ test \\
\hline$<100$ & $13(43.3)$ & $17(20.5)$ & $30(26.6)$ & 0.01 \\
\hline $100-299$ & $15(50.0)$ & $33(39.8)$ & $48(42.5)$ & 0.25 \\
\hline $300-500$ & $0(0)$ & $13(15.7)$ & $13(11.5)$ & 0.02 \\
\hline$>500$ & $2(6.7)$ & $20(24.1)$ & $22(19.5)$ & 0.05 \\
\hline
\end{tabular}

Among the respondents who were aware of glaucoma majority $27(31 \%)$ thought that headache was a symptom of glaucoma, $16(18 \%)$ said it presented with pain in the eyes, whilst $24(28 \%)$ did not know of the presentation of glaucoma. Twelve (14\%) said glaucoma presented with no symptoms.

Of the patients who were aware, more than half, 46 (53\%) obtained their information from a medical personnel .The rest had heard about glaucoma from a family member, $11(13 \%)$ or from the media, $26(30 \%)$.

\section{DISCUSSION}

In the study by Tenkir et al, in South Western Ethiopians, awareness of glaucoma was low $(2.4 \%) .{ }^{12}$ In our study the awareness was high (74\%). The mean age was 54.5 years while in this one the median and modal age group was $50-59$ years. While $43 \%$ of the Ethiopian study was illiterates we found that only $15 \%$ of the participants had no formal education.

But then, $14 \%$ of those without formal education had heard of glaucoma. The association between awareness and attaining high school or better education was statistically significant $(\mathrm{P}<0.0001)^{12}$ which corresponds to our study in which we found the association between awareness and attaining tertiary or better education to be statistically significant. In this study awareness of glaucoma was not associated with age group, gender, ethnic group or religion.

Dandona et al in their study in an urban city in India also found that awareness of glaucoma was low $(2.3 \%)$.

This involved a much larger sample size (1859) and the respondents were aged 15 years and older. ${ }^{14}$ In the study involving urban and rural dwellers in Switzerland, a developed country, Kaweh et al. $(n=383)$ found $76 \%$ did not have any association with the term glaucoma. ${ }^{15}$ They found out that $26 \%$ were unaware. The age ranges in both studies were similar. The high awareness rate in our study may be explained by the fact that the study population was based in a Teaching Hospital specialist clinic and the participants may have received health talks or education. In this study awareness of glaucoma was not associated with age, gender or ethnic group but with middle and tertiary education and income.

In the Switzerland study, awareness of glaucoma was independent of age, gender, educational status and household income. The awareness of glaucoma was 93\% in the study by Atebo et al., conducted in an Australian population. But only $29 \%$ showed some knowledge of glaucoma ${ }^{16}$. The findings are similar to those in this study where out of the $74 \%$ who were aware of glaucoma only $27 \%$ had some knowledge of the presentation of glaucoma.

In the study by Gasch and colleagues in an American population, even though the awareness of glaucoma was high, Hispanics, African Americans and those with less than a college education were likely to be unfamiliar with the disease. In their study even though awareness was high there were no significant differences in the awareness between the ethnic groups. Those with tertiary (college) and middle school education had significant awareness levels. They concluded that although glaucoma awareness in this population was high, Hispanics, African Americans, and those with less than a college education were more likely to be unfamiliar with the disease.

This may be explained by the fact that the disparities in the educational levels in the various ethnic groups are very wide and that may not be the case in Ghana. It is interesting that even in such a hospital based population who are more likely to be better informed from routine health talks; The main source of information was from health workers yet this increased awareness was not necessarily associated with increased knowledge. 
Indeed apart from poor knowledge many still had wrong perceptions on the clinical presentation of glaucoma, believing that glaucoma initially presents with pain and reduced vision.

\section{Limitations}

This is not a population-based study, thus the results may not represent the actual situation in the communities. Patients representing at a teaching hospital may be motivated people and their knowledge and awareness may be more than that of the average population.

The small sample size was also a major limitation.

\section{CONCLUSIONS AND RECOMMENDA- TIONS}

The awareness of glaucoma of patients attending the outpatients Eye Clinic of Komfo Anokye Teaching Hospital is high (74\%). In this study, higher education was the only socioeconomic factor associated with increased awareness, High awareness is associated with tertiary (24\%) and middle school (31\%) education .Increased awareness was not associated with increased knowledge. Among those who were aware of glaucoma there was considerable misconception about glaucoma as only $14 \%$ had accurate knowledge about the symptomless nature of glaucoma.

Awareness of glaucoma seems to be high in a hospital population perhaps as a result of health talks at the clinic but knowledge still remains low and erroneous. There is a need for policy changes to increase awareness program with more emphasis on the contents of the awareness with the intention of better educating patients and targeting the lower socioeconomic populations. This will lead to a better understanding and acceptance of the importance of routine eye examination for early detection and treatment of glaucoma thus reducing visual impairment and preserving quality of life. Community based studies is required to further evaluate the level of awareness and knowledge in primary open angle glaucoma.

\section{REFERENCES}

1. Singh, K., Glaucoma: A global problem Seminars in Ophthalmology 1993. 8 (3): p. 190-195.

2. Friedman, D.S., Wolfs, R.C., O'Colmain, B.J. , Prevalence of open-angle glaucoma among adults in the United States Arch Opthalmol, 2004. 122(4): p. 532-538.

3. Mason, P.K., O. Wilson, M R., National survey of the prevalence and risk factors of glaucoma in $\mathrm{St}$ Lucia , West Indies Ophthalmology . 1989. 96: p. 1363-1368.
4. Leske, M.C., Connell, A.M., Schachat, A.P., The Barbados Eye Study. Prevalence of open angle glaucoma Arch Ophthalmol . 1994112 p. 821829.

5. Quigley, H.A., West, S.K., Rodriguez, J., Munoz, B., Snyder, R The prevalence of glaucoma in a population-based study of Hispanic subjects. . Arch Ophtalmol, 2001. 19: p. 1819-1829.

6. Ntim-Amponsah CT, A.W., Ofosu-Amaah S, Ewusi RK, Idirisuriya-Khair R, Nyatepe-Coo E, Adu-Darko M., Prevalence of glaucoma in an African population. Eye (Lond), 2004. 18(5): p. 4917.

7. Guzek, J.P., Anyomi, F. K., Fiadoyor, S., Nyonator, F, Prevalence of blindness in people over 40 years in the Volta Region of Ghana, West Africa . Ghana Medical Journal 200539.

8. Hyman, L., Wa, S., Connell, A.M.S., Prevalence and causes of visual impairment in the Barbados Eye Study. Ophthalmol, 2001108 p. 1751-1756.

9. Balo, P.K., Wabigira, J., Banla, M., Kuaovi, R.K. , Specific causes of blindness and vision impairment in a rural area of Southern Togo J Français d'Ophthalmologie 2000. 23(5): p. 459-464.

10. Wilson, M.R., Mansour, M., Degnan R., D., Prevalence and causes of low vision and blindness in the extreme north province of Cameroon, West Africa. Ophthalmic Epidemiology 1996 3(1): p. 23-33.

11. Debrah, O. World Glaucoma Week launched in Accra. 2010 [cited 2011 07/03/2011]; Available from: http://www.ghanaweb.com

12. Tenkir, A., Solomon, B., Deribew, A.,. Glaucoma awareness among people attending ophthalmic services in Southwestern Ethiopia BMC Opthalmology 2010 10:17doi:10: p. 1186/147-2415-1017.

13. Bediako, G. Ghana 2010 Population and Housing Censes 2011 [cited 2011 17/04/2011]; Available from: htt://www.ghana.com.

14. Dandona R., D.L., Rajesh K. J, Catherine A. Mcarty \& Society Awareness of eye disease in an urban population in southern India in Bull World Health Organ. 2001 Geneva

15. Kaweh M., S., O., Frances, M. G, Andre, M.,, Awareness about Glaucoma and Related Eye Health Attitudes in Switzerland: A survey of the general public Opthalmologica . 2006 220: p. 101108.

16. Attebo, K.,Mitchell , P,. Knowledge and diseased about common eye diseases.Australian and New Zealand Journal of Ophthalmology .1997. 25 (3):p 283-284 

